\title{
Factors influencing participation of underrepresented students in STEM fields: matched mentors and mindsets
}

\author{
Katherine Kricorian*, Michelle Seu, Daniel Lopez, Elsie Ureta and Ozlem Equils
}

\begin{abstract}
Background: Women and ethnic minorities remain underrepresented in science, technology, engineering, and math (STEM) fields. The goal of this pilot study is to better understand the beliefs and experiences of underrepresented US students pursuing STEM. Our focus was to gain insights into their mentorship experiences and preferences regarding having mentors who are gender and ethnicity matched. Environmental and psychological factors associated with participants' decision to pursue STEM, such as family influences, academic mindsets, and attitudes towards STEM, were also studied.
\end{abstract}

Methods: We developed a survey tool based on published literature and established instruments, including measures of STEM belonging, science identity, and growth mindset, as well as measures assessing students' views on their STEM participation. We surveyed members of a STEM-focused non-profit who were in college, graduate school, or were recent graduates.

Results: Forty-eight adults currently pursuing STEM responded to the survey. The majority (71\%) were female and nearly all (96\%) identified as an ethnic minority. Most reported knowing someone of their same gender (68\%) or ethnicity (66\%) with a STEM career who served as a role model. The majority (54\%) stated that meeting a STEM professional of their own gender and ethnicity would be effective encouragement to pursue STEM. A similar percentage (56\%) believed that media exposure to gender- and ethnicity-matched STEM professionals would be effective encouragement. Most (73\%) demonstrated a growth mindset and had strong family support to pursue STEM (68\%). Only two-thirds (66\%) felt they belonged in STEM careers, and 30\% agreed that people in their STEM classes are a lot like them.

Conclusion: This study contributes additional information on the views and experiences of diverse students actively pursuing STEM. Most participants indicated the importance of meeting and being mentored in STEM by those of their same gender and ethnicity, either in person or through media. Future educational efforts to increase STEM diversity should consider students' mentorship preferences and facilitate interactions with matched-background mentors accordingly, with consideration given to the use of media. Educators should focus on inclusive learning by highlighting the accomplishments of diverse STEM professionals, to help strengthen feelings of STEM belonging.

Keywords: Mentoring, Media models, Ethnicity, Gender, Representation, Belonging, Identity, Mindsets, STEM

*Correspondence: krn830@gmail.com
MiOra, 17328 Ventura Blvd No. 190, Encino, CA 91316, USA

(0) The Author(s). 2020 Open Access This article is licensed under a Creative Commons Attribution 4.0 International License, which permits use, sharing, adaptation, distribution and reproduction in any medium or format, as long as you give appropriate credit to the original author(s) and the source, provide a link to the Creative Commons licence, and indicate if changes were made. The images or other third party material in this article are included in the article's Creative Commons licence, unless indicated otherwise in a credit line to the material. If material is not included in the article's Creative Commons licence and your intended use is not permitted by statutory regulation or exceeds the permitted use, you will need to obtain permission directly from the copyright holder. To view a copy of this licence, visit http://creativecommons.org/licenses/by/4.0/. 


\section{Background}

Women are significantly underrepresented in STEM (science, technology, engineering, and mathematics) fields in the USA, making up less than a quarter of those working in STEM occupations (Noonan, 2017; Ong, Smith, \& Ko, 2018). Representation of women of color is even lower, with Hispanic, Asian, and African American women each receiving less than 5\% of STEM bachelor's degrees in the USA (Ong et al., 2018; National Center for Education Statistics, 2017). People of color are also underrepresented in US STEM leadership positions across the industry, academia, and the federal workforce (Wu \& Jing, 2013). Increasing representation of women and people of color in STEM fields can help increase diversity, creativity, and innovation in STEM. However, there is limited data available on underrepresented students who are pursuing STEM careers regarding factors associated with their participation in STEM.

Several factors may influence participation of underrepresented students in STEM. These may include both intrinsic psychological factors and external environmental variables, such as their mentorship experiences and preferences, their academic mindsets, STEM attitudes, and family background characteristics. By examining the views and experiences of diverse STEM students across these domains, insights can be gained which may help develop strategies to facilitate STEM participation by other underrepresented students.

One factor thought to be relevant to persistence and success in STEM is the academic mindset or the psychology and key beliefs of a student (Rattan, Savani, Chugh, \& Dweck, 2015; Walton, 2014). An important academic mindset is whether students feel a sense of "belonging" or acceptance and fit in STEM (Ito \& McPherson, 2018). Prior research suggests that gender and ethnicity can impact feelings of acceptance, with students from underrepresented groups reporting more uncertainty about whether they belong in their academic fields than students from well-represented demographic groups (Ito \& McPherson, 2018; Walton \& Cohen, 2007; Zaniewski \& Reinholz, 2016). Feelings of belonging and interest in STEM contribute to a student's STEM identity or the degree to which someone perceives STEM to be a key component of their sense of self (Kim \& Sinatra, 2018; Robnett, Nelson, Zurbriggen, Crosby, \& Chemers, 2018). Another academic mindset that can influence STEM participation is whether students view intelligence as fixed and something they cannot change (fixed mindset) or instead view it as something that can be developed over time with effort and dedication (a growth mindset). Growth mindsets have been found to especially benefit women and underrepresented minorities in math and science (Rattan et al., 2015).
Feeling a greater sense of belonging in STEM can have a positive impact on academic achievement and retention in STEM, particularly for women and students of color (Rattan et al., 2015). STEM belonging in underrepresented students may be influenced by relationships with mentors (Robnett et al., 2018). Mentoring is thought to be one possible approach to engage and retain more students in STEM, and mentoring relationships may be particularly helpful to improve diversity in STEM among underrepresented groups. However, limited data are available from minority STEM students regarding their mentorship experiences and preferences, as relatively few studies have explored whether having a mentor of the same ethnicity and gender (a matchedbackground mentor) is personally important to women and students of color in STEM. Past studies have largely focused on populations that are well-represented in STEM, such as Caucasian males, but there remains a need to better understand how experiences may differ in women and students of color who have demonstrated persistence in STEM.

Research has shown that women and men form gender roles in childhood, largely based on their exposure to media and popular culture (Olsson and Martiny 2018; Steinke, 2017). Media images often depict men and women in traditional gender roles, which can negatively impact the STEM career choices women make (Olsson and Martiny 2018; Bian, Leslie, \& Cimpian, 2017). Dou, Hazari, Dabney, Sonnert, and Sadler (2019) found that talking with friends and family about science and consuming science media in childhood were predictive of STEM identity in college. The types of media that students are being exposed to are rapidly changing, and the current generation of students spends a great deal of time interacting with media platforms and gaining exposure to social media influencers (Pew Research Center, 2019). Exposure to ethnically diverse STEM professionals through media (including social media) might be utilized to support and encourage underrepresented students to pursue STEM either instead of, or in addition to, live interaction. Media exposure could be particularly valuable given the scarcity of female and underrepresented minority professionals available to serve as mentors and role models to potential STEM students. By analyzing mentor characteristics that are important to minority STEM students, researchers can better determine how media exposure to STEM professionals can be used to support their career goals.

This pilot study's objective is to better understand the perspectives and experiences of underrepresented students in STEM across several domains which may be associated with their STEM participation. The study population is unique in that it consists of nearly all women and people of color who are actively pursuing a 
career in STEM, most of whom have demonstrated STEM persistence through at least their second year of college. Our focus was to gain insights into their mentorship experiences and preferences regarding exposure to a gender- and ethnicity-matched mentor, either in person or through media, to help determine what mentor characteristics would motivate underrepresented students to pursue STEM careers. We also surveyed the respondents on environmental and psychological factors that may be associated with their decision to pursue STEM, such as childhood and family influences, attitudes towards STEM, and their academic mindsets regarding science identity, growth mindset, and feelings of STEM belonging.

\section{Methods}

We developed a survey tool based on published literature and previously used instruments which included measures of STEM belonging (Lewis et al., 2017), science identity (Vincent-Ruz \& Schunn, 2018), and growth mindset (Rattan et al., 2015; Leslie, Cimpian, Meyer, \& Freeland, 2015), as well as measures assessing students' views on their STEM participation. The Institutional Review Board (IRB) indicated the study is exempt under 45 Code of Federal Regulations (CFR) $\mathbb{\$}$ 46.104(d)(2) because this is an anonymous survey study. Consent to participate was obtained after students were given sufficient information about the survey and asked if they wanted to complete an anonymous survey. In order to protect subject privacy, no names or identifiers were collected. We emailed the survey to the members of a STEM-focused educational non-profit organization (MiOra) and peer contacts in STEM fields. The educational nonprofit has a mission to improve diversity in STEM, with a focus on serving women and underrepresented minorities. Data was collected between June 2019 and February 2020. Descriptive statistics were used to report the results of students' views on their participation in STEM across several domains including family background, importance of mentor match, STEM attitudes, and academic mindsets.

\section{Results}

A total of 48 subjects who are pursuing STEM completed the survey, and all were adults age 18 years or older (mean age $25.4 \pm 7.8$ years). The majority $(71 \%)$ of survey respondents were female. Nearly all were students of color: $46 \%$ were Hispanic, $42 \%$ Asian-American, $8 \%$ African-American, and 4\% Caucasian. Gender proportions were consistent across ethnicities. A total of 5\% were high school students, $52 \%$ were college students (mostly juniors and seniors), $11 \%$ were graduate or medical school students, and 32\% were recent graduates. Respondents' parent education levels were relatively high:
$32 \%$ had completed high school or less, $8 \%$ had attended technical school, 33\% had at least some college, and $27 \%$ had attended graduate school.

\section{Childhood STEM experiences and family influences}

Participants were asked about their childhood STEM experiences and family influences, and they rated specific characteristics as either true or false about themselves when they were a child (12 years old or younger; Fig. 1). Approximately one third of the respondents reported having a parent in a STEM career, and most $(68 \%)$ had parents who encouraged them to pursue STEM careers. The majority knew someone of their same gender $(68 \%)$ or their same ethnicity $(66 \%)$ with a STEM career outside their families to serve as a role model while growing up. About half stated that they watched shows or movies that featured people of their same gender $(55 \%)$ or ethnicity (43\%) with STEM careers. Overall, these students tended to have strong parental support and exposure to role models of their same ethnicity or gender to encourage them to pursue STEM. They wanted to have a STEM career from a young age and enjoyed STEMrelated media as children. Importantly, about one-third (32\%) did not believe people like themselves had STEM careers.

\section{Gender- and ethnicity-matching preferences}

When students were asked what would encourage others of their same gender and ethnicity to pursue a STEM career, over half of the respondents (54\%) stated that meeting STEM professionals of their own gender and ethnicity would be effective encouragement, whereas $39 \%$ stated that meeting STEM professionals of any gender or ethnicity would be effective (Fig. 2). Most respondents $(56 \%)$ also agreed that exposure to media (social media, TV, etc.) featuring STEM professionals of their own gender and ethnicity would be effective encouragement versus 39\% who stated that media featuring STEM professionals in general would be effective (Fig. 2). Notably, the data suggested that exposure to ethnicity- and gender-matched STEM professionals in the media is equally as likely to encourage students to pursue STEM careers as meeting those same STEM professionals in person (56\% vs. $54 \%$; Fig. 2).

\section{Familiarity with diverse STEM professionals}

Participants were asked whether it would be easy for them to name STEM professionals of particular gender and ethnicity combinations, in order to understand their familiarity with diverse STEM professionals. We also asked about their ability to name social media influencers of the same gender and ethnicity combinations, to provide a comparison point. Less than $30 \%$ of respondents could easily name a Hispanic or African-American 


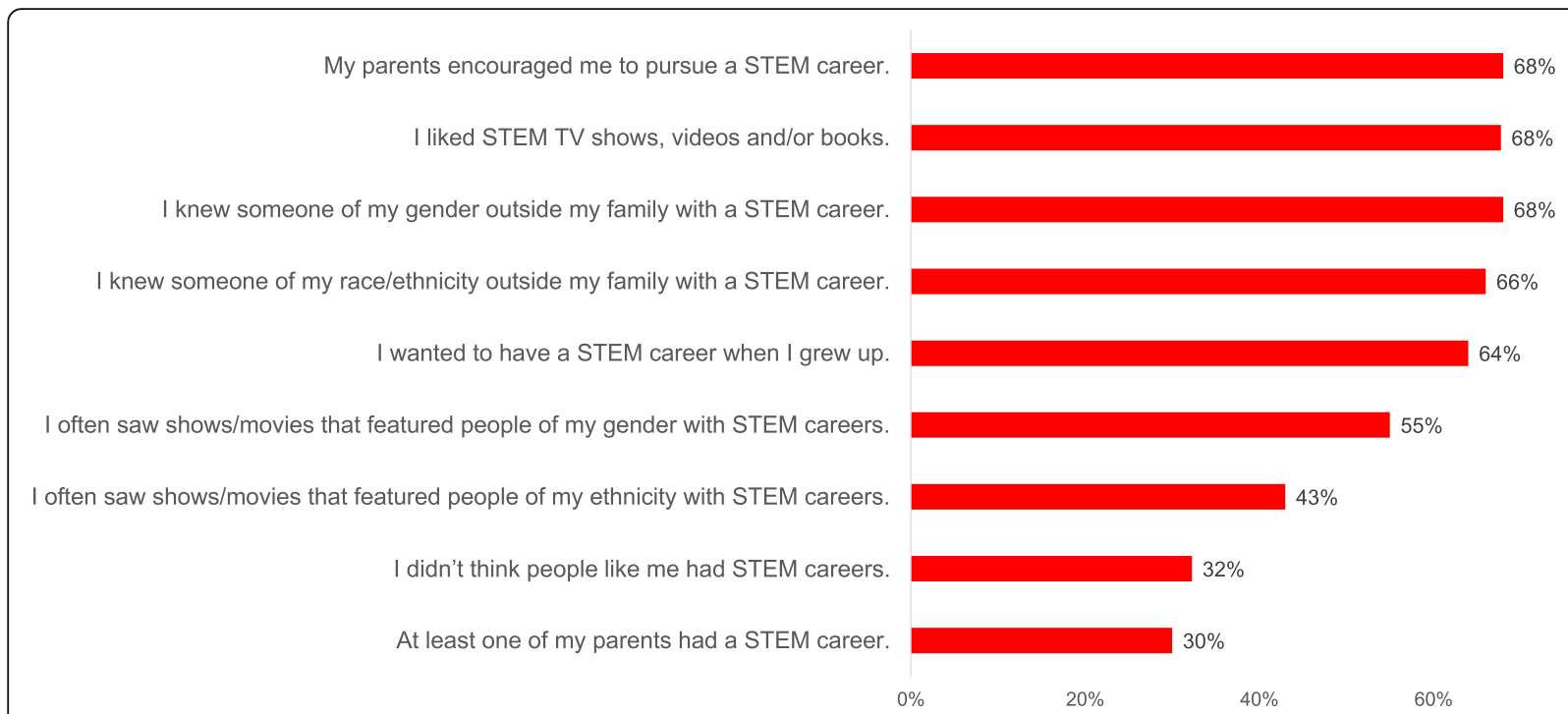

Fig. 1 Childhood STEM experiences and family influences. Which of the following were true about you when you were a child (12 years or younger)?

STEM professional of either gender, whereas twice as many $(62 \%)$ could name a white male STEM professional (Fig. 3). Although the majority of respondents identified themselves as female, they were 4 times as likely to be able to name a white male than an African-American female STEM professional (62\% vs. 13\%; Fig. 3). Twice as many respondents could name an African-American female social media influencer vs. STEM professional (33\% vs. 13\%; Fig. 3). These results suggest that surveyed students may have greater familiarity with Hispanic and AfricanAmerican female social media influencers than STEM professionals. The relatively low ability to name STEM professionals, unless those professionals are Caucasian males, indicates a broad opportunity to increase awareness of diverse STEM professionals through media exposure.

\section{STEM attitudes and academic mindsets}

To better understand students' reasons for pursuing a STEM career, participants were asked to rate their beliefs and attitudes towards STEM on a 1 to 6 scale where 1 represented "strongly disagree" and 6 represented "strongly agree." The percentage of responses in the two top categories (strongly agree or agree) is summarized in Fig. 4. Most respondents agreed that STEM topics excite

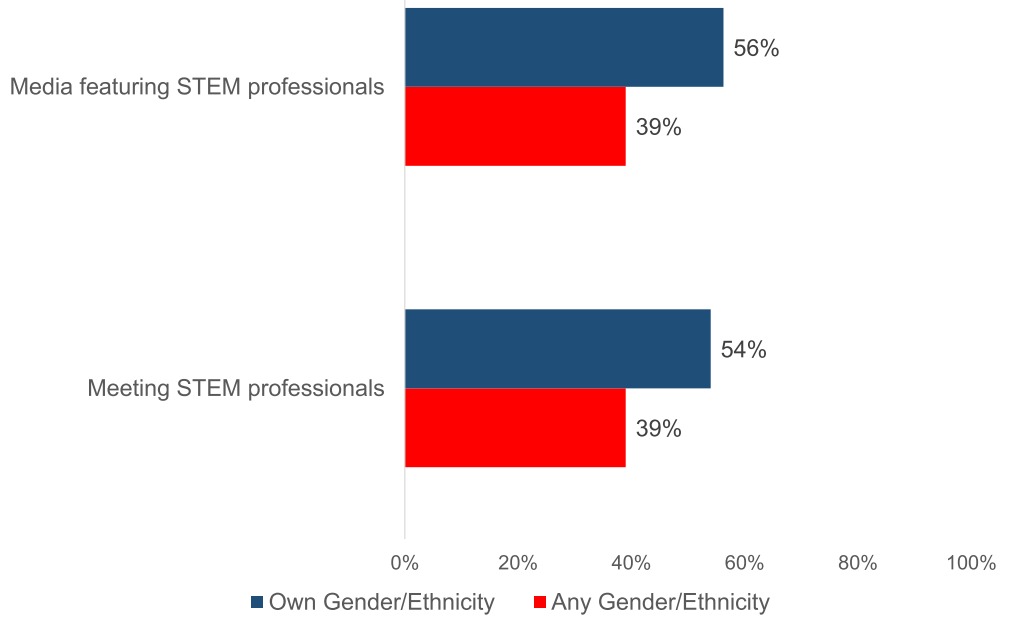

Fig. 2 Preferences regarding gender- and ethnicity-matched mentors. What do you think would encourage more people of your gender and ethnicity to pursue STEM careers? The majority of respondents (54\%) believed that exposure to a STEM professional of their own gender and ethnicity would encourage them to pursue STEM. A similar percentage (56\%) believed that media exposure to gender- and ethnicity-matched STEM professionals would be effective encouragement 


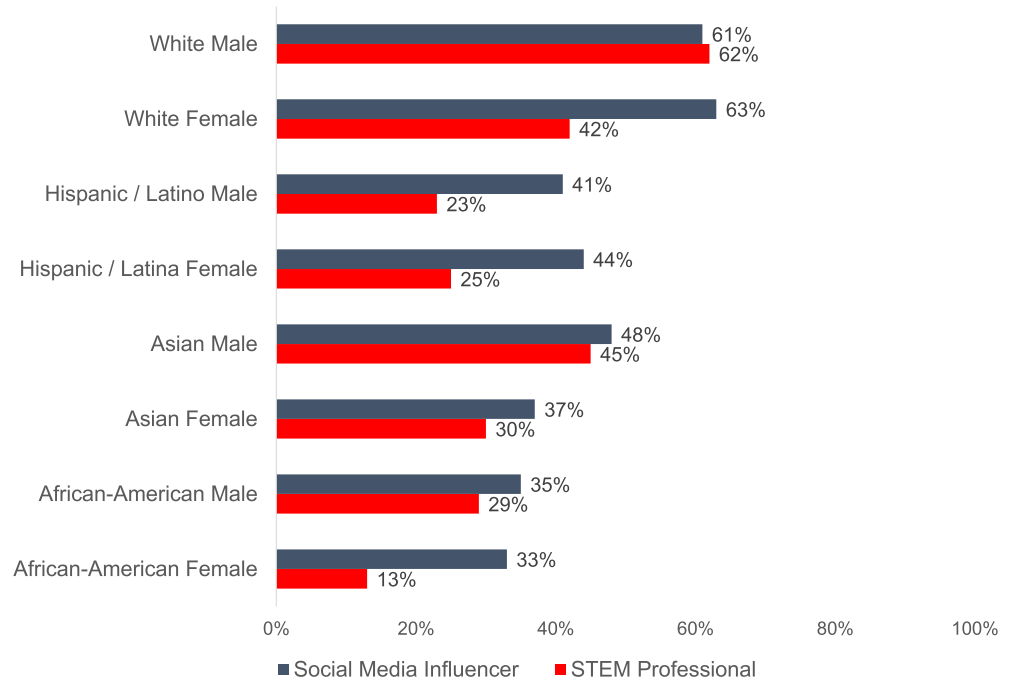

Fig. 3 Familiarity with diverse STEM professionals. Which of the following can you name easily? Respondents were 4 times as likely to be able to name a Caucasian male than an African-American female STEM professional (62\% vs. 13\%). Twice as many respondents could name an AfricanAmerican female social media influencer vs. STEM professional (33\% vs. 13\%)

their curiosity (85\% strongly agreed/agreed) and that doing STEM is cool (83\%), suggesting they found their STEM studies interesting and meaningful. Recreational and social enjoyment of STEM was common, but not universal. About $60 \%$ agreed they like to talk with their friends or family about STEM. Approximately half (49\%) said they follow STEM news on social media/websites, and $47 \%$ indicated they watch movies or shows about STEM careers. Despite respondents' positive attitudes toward STEM and interest in STEM careers, approximately half felt STEM careers were too expensive (46\%) and required too much schooling (46\%), and 17\% indicated that STEM careers were too hard.
Prior research has shown that a sense of belonging and a positive STEM identity can be associated with interest and retention in STEM (Rainey, Dancy, Mickelson, Stearns, \& Moller, 2018; Kim \& Sinatra, 2018). We surveyed participants regarding their academic mindsets, based on previously used instruments which included measures of STEM belonging (Lewis et al., 2017), growth mindset (Rattan et al., 2015; Leslie et al., 2015), and science identity (Vincent-Ruz \& Schunn, 2018). Respondents rated their agreement on a 1 to 6 scale, where 1 represented "strongly disagree" and 6 represented "strongly agree." The percentage of responses in the two top categories (strongly agree or agree) is summarized in

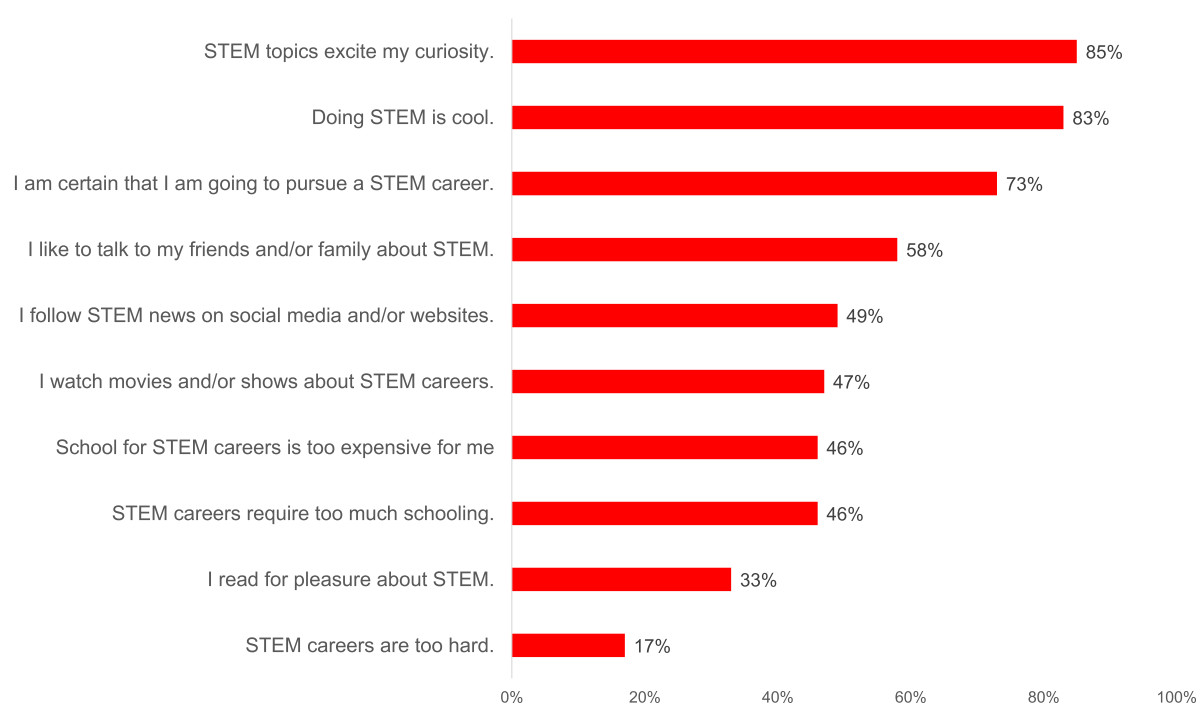

Fig. 4 Agreement with STEM attitude statements (percentage of respondents who strongly agree/agree) 
Fig. 5. Although respondents were pursuing STEM careers, not all agreed that they saw themselves as a STEM person $(66 \%)$ or that people like them belong in STEM careers (66\%). Only 30\% agreed that people in their STEM classes were a lot like them. Respondents demonstrated growth mindsets: they agreed that with the right amount of effort and dedication, anyone can become a top scholar in STEM (73\%). Consistently, only about $30 \%$ thought that a special ability which cannot be taught is needed to be a top STEM scholar.

\section{Discussion and conclusions}

The goal of this pilot study was to better understand the beliefs and experiences of underrepresented students who are actively pursuing a career in STEM. A unique aspect of this study is its focus on a diverse population that is nearly all women and people of color, a group for which limited data are available. We sought to describe the views of this cohort across key domains associated with their participation in STEM. By examining the preferences and attitudes of these unique students, we can gain insights into factors associated with their decision to pursue STEM, which may help develop strategies and interventions to encourage more underrepresented students to do the same.

Few studies have assessed the importance of mentor attributes by focusing on the experiences and preferences of women and minorities successfully pursuing STEM careers. In this study, the majority of respondents knew someone of their same gender $(68 \%)$ or their same ethnicity (66\%) with a STEM career outside their families to serve as a role model while growing up. Most participants indicated the importance of meeting and being mentored in STEM by someone of their same gender and ethnicity. Given the scarcity of female and minority professionals who are available to be one-on-one, inperson mentors to potential STEM students, this study also examined whether mentoring could be accomplished virtually through media so that each STEM professional could extend their mentoring impact. Interestingly, most students believed that media exposure to ethnicity- and gender-matched STEM professionals would be effective encouragement to pursue STEM. These findings have implications that can potentially be used to help increase the representation of women and students of color in STEM fields. Educators can help build interest in STEM and encourage underrepresented students to pursue STEM careers by asking about their mentorship preferences and then connecting students with mentors accordingly, with consideration given to the use of virtual interaction through media.

Previous studies have examined mentorship through online networks and its outcomes. Blake-Beard, Bayne, Crosby, and Muller (2011) followed students who used an online mentoring network (MentorNet) and were linked to distal mentors primarily through text-based media (e.g., e-mail). The investigators found that having a virtual, e-mail-based mentor who was matched in gender or race was important to women and students of color and led to increased mentoring help being

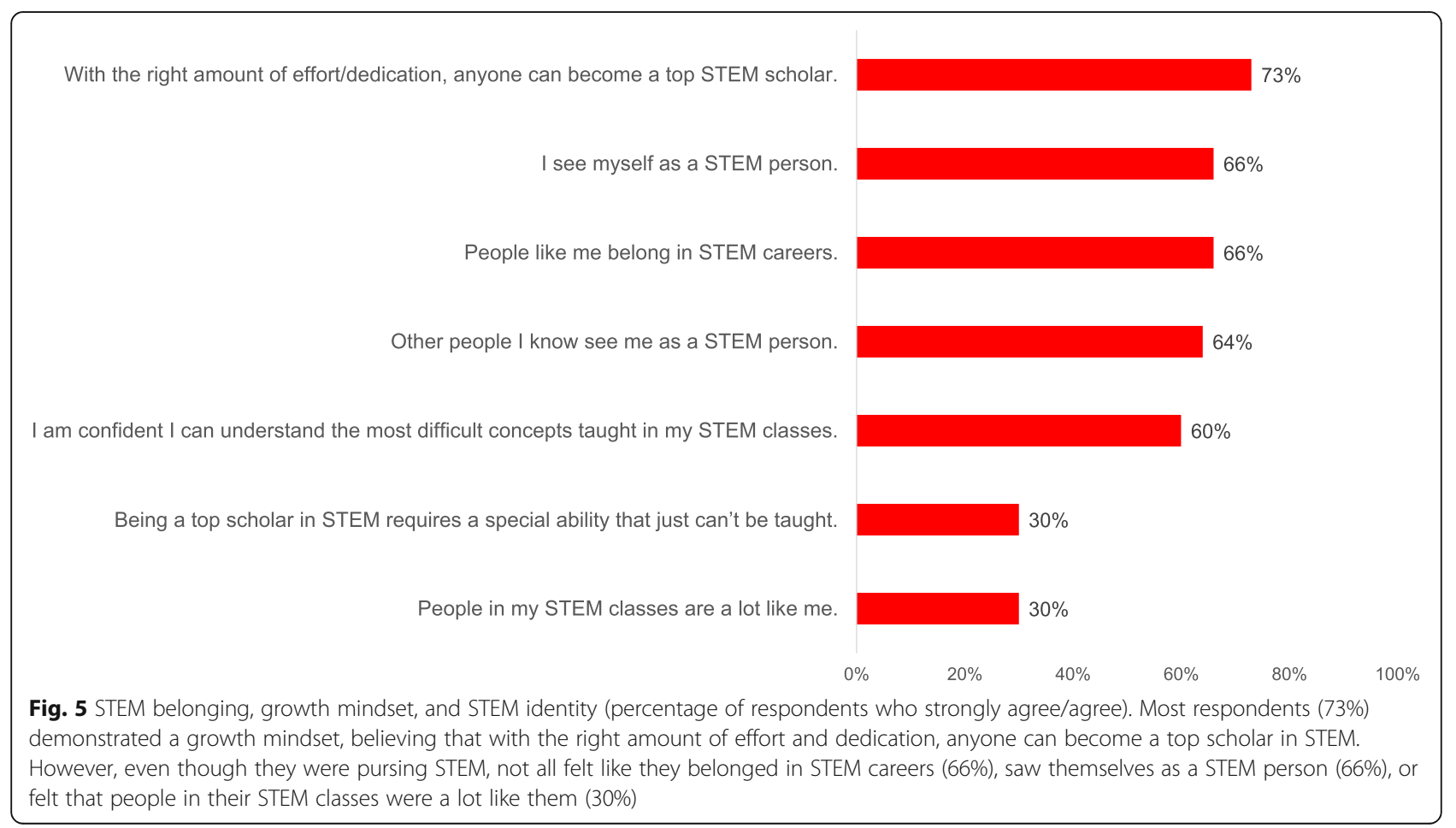


provided. However, students who were mentor-matched did not have improved academic outcomes. Dennehy and Dasgupta (2017) examined the impact of traditional live peer mentoring and found evidence that it did improve outcomes. In that study, freshman women engineering majors who were assigned a female (but not male) peer mentor experienced greater belonging, confidence, and retention in their engineering major throughout college. The population examined in that study consisted of predominantly Caucasian students.

The results of our current study provide novel information and extend prior research by providing data on the views of a cohort that is almost exclusively nonCaucasian students of color, with the largest percentage of respondents surveyed identifying as Hispanic. The number of students of color in our sample contributes additional insights into this unique population in STEM. While our study did not directly examine student outcomes, nearly all of the students surveyed in our cohort successfully persisted in STEM through at least their second year of college, having made it through a period traditionally associated with significant drop-out from STEM fields.

The consideration of media as a potential pathway for mentorship may represent a more novel and modern approach to mentor interactions. The current generation of students, and minority students in particular, are spending a large percentage of their time interacting with media (Montgomery, 2018; Pew Research Center, 2019). We found that women and students of color are relatively familiar with minority social media influencers, but may not have been exposed to media depictions of minority female STEM professionals to the same extent. Most surveyed students indicated that matched mentorship through virtual media could be effective and this approach may have important differences from emailbased interaction. Mentorship via text-based media (e.g., email), as studied by Blake-Beard et al. (2011), may not contain the visual and auditory information that could convey important similarities between mentors and mentees. These similarities may help mentees identify more closely with mentors. Perhaps, use of media-based mentoring interactions that include such visual and auditory cues between mentors and mentees could lead to more positive outcomes from virtual mentorship than email-based mentoring. Women and minority STEM professionals on social media may be well positioned to have a positive influence on the STEM identity of underrepresented students. This area is ripe for further research, especially as improved technology continues to make mediated interactions more multisensory and realistic.

Researchers and educators should explore opportunities to provide mentorship exposure through media and assess its impact and potential benefits. Using digital media for exposure to role models and mentors can help to reduce financial and time burdens on current female and minority STEM professionals. Although only half of the respondents indicated they watched shows that featured STEM professionals of their same gender or ethnicity in childhood, they may not watch these media simply because the media is not widely produced. Most currently available STEM shows and movies feature Caucasian males, highlighting the opportunity for greater gender and ethnic representation in media.

We also found that family context during childhood appears to have been important in motivating students in this cohort to seek STEM careers. Most students reported they wanted a STEM career from a young age, enjoyed STEM-related media as children, and had families that encouraged them to pursue a STEM career. Nearly 60\% said they currently talk to their families and friends about STEM. Family encouragement and support have been found to be important factors in students' ability to amass the social and cultural capital required for educational success (Mishra, 2020). Prior research has shown that positive academic reinforcement, especially from family members, is associated with improved educational achievement among minority students, even if those family members did not attend college themselves (Elliott and Bachman 2018). Specific to STEM, parental involvement and interaction are thought to have important influences on students' science engagement and identification with science. Talking with friends and family about science and exposure to science media in childhood have been shown to predict STEM identity in college (Dou et al., 2019). The influence of family support in the success of women and students of color in STEM should be further investigated, to assess strategies that could strengthen familial advocacy for youth aspiring to enter STEM fields.

Helping women and minorities develop strong identities and academic mindsets related to STEM is a potential opportunity to address underrepresentation in STEM. Surveyed students tended to demonstrate growth mindsets, largely agreeing that with the right amount of effort and dedication, anyone can become a top scholar in STEM (73\%) and disagreeing that success in STEM requires a special ability which cannot be taught. Although respondents were students pursuing STEM, not all felt they belonged in STEM (66\%) or saw themselves as a STEM person (66\%). Less than a third (30\%) agreed that people in their STEM classes were a lot like them. Our data provide some evidence that these beliefs started to form early in childhood, as about one third (32\%) of respondents recalled that, as children, they did not think people like them had STEM careers. This feeling of not belonging, coupled with minority students' 
inherent challenges with pursuing a STEM education, could lead some to feelings of alienation and eventual abandonment of the STEM career path. Access to matched mentors, whether through traditional in-person mentorship or digitally through visual media, could potentially help strengthen feelings of belonging and STEM identity among minority students and should be explored further.

The current research is not without limitations. The survey conducted had a limited number of respondents who were members of a STEM-focused non-profit community whose mission is to improve diversity in STEM fields. Future research should be done with larger populations that include Caucasian students, and/or in a mixed method study, so that comparisons between gender and racial groups can be further explored. Additional research should assess whether underrepresented students' STEM pursuits are impacted by visual media exposure to matched STEM mentors and whether this exposure is causally associated with increased feelings of STEM belonging, stronger STEM identity, and improved outcomes in STEM. If so, media-based mentors could be further utilized to support participation and retention of underrepresented students in STEM fields. By having students and role models of the same gender and ethnicity connected through media, minority students may find it easier to envision themselves working in STEM fields. This is an important area for future research.

In conclusion, this study provides additional information towards understanding the views and experiences of women and students of color who are pursuing STEM. The findings have implications for strategies and interventions that can potentially be used by educators to help support STEM participation among diverse students. Respondents reported strong family support to pursue STEM subjects, stated that STEM topics excited their curiosity, and largely demonstrated a growth mindset. Most indicated the importance of being mentored in STEM by those of their same gender and ethnicity, either in person or through media. Future educational efforts to increase diversity in STEM fields should take students' mentorship preferences into account and facilitate interactions with matched-background mentors accordingly, with consideration given to the use of visual media-based interaction. Although students were actively pursuing STEM, not all felt like they belonged in STEM careers or that people in their STEM classes are a lot like them. Educators should focus on inclusive learning by highlighting the accomplishments of diverse STEM professionals more broadly, both in the classroom and through media, to help strengthen feelings of STEM belonging.

\section{Abbreviations}

CFR: Code of Federal Regulations; IRB: Institutional Review Board:

STEM: Science, technology, engineering, and mathematics

\section{Acknowledgements}

We thank Bryk Li of MiOra for his help with the survey data collection. We thank Dr. Tiffany Ito, Professor Psychology and Neuroscience, University of Colorado Boulder, for providing input to our study design and for her review and comments. We also thank the study participants.

\section{Authors' contributions}

KK, MS, and OE designed the study, and all authors contributed to the data collection, analysis, and interpretation of the data. All authors contributed to the writing and revising of the paper. The authors read and approved the final manuscript.

\section{Funding}

This project was supported by MiOra, an educational nonprofit organization based in Los Angeles, CA.

\section{Availability of data and materials}

The dataset generated and analyzed during this study is available from the corresponding author on reasonable request.

\section{Competing interests}

The authors declare that they have no competing interests.

Received: 17 December 2019 Accepted: 15 April 2020

Published online: 21 April 2020

\section{References}

Bian, L., Leslie, S. J., \& Cimpian, A. (2017). Gender stereotypes about intellectual ability emerge early and influence children's interests. Science, 355(6323), 389-391.

Blake-Beard, S., Bayne, M. L., Crosby, F. J., \& Muller, C. B. (2011). Matching by race and gender in mentoring relationships: keeping our eyes on the prize. Journal of Social Issues, 67(3), 622-643.

Dennehy, T. C., \& Dasgupta, N. (2017). Female peer mentors early in college increase women's positive academic experiences and retention in engineering. Proceedings of the National Academy of Sciences of the United States of America (PNAS), 114(23), 5964-5969. https://doi.org/10.1073/pnas. 1613117114.

Dou, R., Hazari, Z., Dabney, K., Sonnert, G., \& Sadler, P. (2019). Early informal STEM experiences and STEM identity: the importance of talking science. Science Education, 103(3), 623-637.

Elliott, L., \& Bachman, H.J. (2018). Parents educational beliefs and children's early academics: examining the role of SES. Children and Youth Services Review, 91, 11-21. https://doi.org/10.1016/j.childyouth.2018.05.022

Ito, T. A., \& McPherson, E. (2018). Factors influencing high school students' interest in PSTEM. Frontiers in Psychology, 9, 1535. https://doi.org/10.3389/ fpsyg.2018.01535.

Kim, A. Y., \& Sinatra, G. M. (2018). Science identity development: an interactionist approach. International Journal of STEM Education, 5, 51. https://doi.org/10. 1186/s40594-018-0149-9.

Leslie, S. J., Cimpian, A., Meyer, M., \& Freeland, E. (2015). Expectations of brilliance underlie gender distributions across academic disciplines. Science, 347(6219), 262-265.

Lewis, K.L., Stout, J.G., Finkelstein, N.D., Pollock, S.J., Miyake, A., Cohen, G.L., \& Ito, T. A. (2017). Fitting in to move forward: belonging, gender, and persistence in the physical sciences, technology, engineering, and mathematics (pSTEM). Psychology of Women Quarterly, 1-17. https://doi.org/10.1177/ 0361684317720186

Mishra, S. (2020). Social networks, social capital, social support and academic success in higher education: a systematic review with a special focus on "underrepresented" students. Educational Research Review, 29. https://doi.org/ 10.1016/.jedurev.2019.100307

Montgomery, B. L. (2018). Building and sustaining diverse functioning networks using social media and digital platforms to improve diversity and inclusivity. Frontiers in Digital Humanities, 5, 22. https://doi.org/10.3389/fdigh.2018.00022.

National Center for Education Statistics, U.S. Department of Education "Table 318. 45: Number and Percentage Distribution of Science, Technology, Engineering, and Mathematics (STEM) Degrees/Certificates Conferred by Postsecondary Institutions, by Race/Ethnicity, Level of Degree/Certificate, and Sex of Student: 2008-09 through 2015-16," Digest of Education Statistics: 2016 
Tables and Figures (2017). Retrieved from: https://nces.ed.gov/programs/ digest/d17/tables/dt17_318.45.asp?referer=raceindicators

Noonan, R. Women in STEM: 2017 update (ESA Issue Brief \#06-17). Office of the Chief Economist, Economics and Statistics Administration, U.S. Department of Commerce (November 13, 2017). Retrieved from https://www.commerce. gov/news/fact-sheets/2017/11/women-stem-2017-update

Olsson, M., \& Martiny, S. E. (2018). Does exposure to counterstereotypical role models influence girls' and women's gender stereotypes and career choices? A review of social psychological research. Frontiers in Psychology, 9, 2264. https://doi.org/10.3389/fpsyg.2018.02264.

Ong, M., Smith, J. M., \& Ko, L. T. (2018). Counterspaces for women of color in STEM higher education: marginal and central spaces for persistence and success. Journal of Research in Science Teaching, 55(2), 206-245. https://doi. org/10.1002/tea.21417.

Pew Research Center (2019). Social media fact sheet. Retrieved from: https:// www.pewresearch.org/internet/fact-sheet/social-media/

Rainey, K., Dancy, M., Mickelson, R., Stearns, E., \& Moller, S. (2018). Race and gender differences in how sense of belonging influences decisions to major in STEM. International Journal of STEM Education, 5:10. https://doi.org/10. 1186/s40594-018-0115-6.

Rattan, A., Savani, K., Chugh, D., \& Dweck, C. S. (2015). Leveraging mindsets to promote academic achievement: policy recommendations. Perspectives on Psychological Science, Vol, 10(6), 721-726.

Robnett, R.D., Nelson, P.A., Zurbriggen, E.L., Crosby, F.J., \& Chemers, M.M. (2018). Research mentoring and scientist identity: insights from undergraduates and their mentors. International Journal of STEM Education. 5:41. https://doi.org/ 10.1186/s40594-018-0139-y.

Steinke, J. (2017). Adolescent girls' STEM identity formation and media images of STEM professionals: considering the influence of contextual cues. Frontiers in Psychology, 8, 716. https://doi.org/10.3389/fpsyg.2017.00716.

Vincent-Ruz, P., \& Schunn, C.D. (2018). The nature of science identity and its role as the driver of student choices. International Journal of STEM Education, 5:48. https://doi.org/10.1186/s40594-018-0140-5.

Walton, G. M. (2014). The new science of wise psychological interventions. Current Directions in Psychological Science, 23(1), 73-82. https://doi.org/10, 1177/0963721413512856.

Walton, G. M., \& Cohen, G. L. (2007). A question of belonging: race, social fit and achievement. Journal of Personality and Social Psychology, 92(1), 82-96.

Wu, L., \& Jing, W. (2013). Leadership hurdles. Nature, 493, 125-126. https://doi. org/10.1038/nj7430-125a.

Zaniewski, A. M., \& Reinholz, D. (2016). Increasing STEM success: a near-peer mentoring program in the physical sciences. International Journal of STEM Education, 3, 14. https://doi.org/10.1186/s40594-016-0043-2.

\section{Publisher's Note}

Springer Nature remains neutral with regard to jurisdictional claims in published maps and institutional affiliations.

\section{Submit your manuscript to a SpringerOpen ${ }^{\circ}$ journal and benefit from:}

- Convenient online submission

- Rigorous peer review

- Open access: articles freely available online

- High visibility within the field

- Retaining the copyright to your article

Submit your next manuscript at $\boldsymbol{\nabla}$ springeropen.com 